Article

\title{
Movement of Inflation and New Keynesian Phillips Curve in ASEAN
}

\author{
Adhitya Wardhono*(D, M. Abd. Nasir, Ciplis Gema Qori'ah and Yulia Indrawati
}

check for

updates

Citation: Wardhono, Adhitya, M. Abd. Nasir, Ciplis Gema Qori'ah, and Yulia Indrawati. 2021. Movement of Inflation and New Keynesian Phillips Curve in ASEAN. Economies 9: 34. https://doi.org/10.3390/ economies 9010034

Received: 31 December 2020

Accepted: 22 February 2021

Published: 10 March 2021

Publisher's Note: MDPI stays neutral with regard to jurisdictional claims in published maps and institutional affiliations.

Copyright: (c) 2021 by the authors. Licensee MDPI, Basel, Switzerland. This article is an open access article distributed under the terms and conditions of the Creative Commons Attribution (CC BY) license (https:/ / creativecommons.org/licenses/by/ $4.0 /)$.
Department of Economics, Faculty of Economics and Business, University of Jember, Jl. Kalimantan 37, Jember 68121, East Java Province, Indonesia; abd.nasir@unej.ac.id (M.A.N.); ciplisqoriah@unej.ac.id (C.G.Q.); yulia.feb@unej.ac.id (Y.I.)

* Correspondence: adhitya.wardhono@unej.ac.id

\begin{abstract}
The development of the theory of dynamic inflation begins by linking wage inflation and unemployment. In further developments, factor of expectation is classified into inflation model. The study used inflation data is important for ASEAN, because ASEAN is one of the strengths of the international economy. This study analyzes the dynamics of inflation in the ASEAN using framework the New-Keynesian Phillips Curve (NKPC) model. The data used is the quarterly panel data from 5 ASEAN members in the period 2005.QI-2018.QIV. The study of this dynamic inflation applies quarter to quarter inflation data, meaning that the inflation rate is the percentage change in the general price of the current quarter compared to last quarter general price divided by the last quarter. The empirical results are estimated by using the Generalized Method of Moment (GMM), both of the system and first different indicates that the pattern formation of inflation expectations are backward-looking and forward-looking. In addition, the estimated NKPC models show the backward-looking behavior is more dominant than the forward looking. Changes in inflation are not entirely influenced by expectations of inflation in each country. Changes in inflation are also influenced by the output gap, changes in money supply, and exchange rate. Based on the findings of this study, it can be concluded that the NKPC models can explain the dynamics of inflation in each country in the ASEAN region.
\end{abstract}

Keywords: dynamic inflation; ASEAN; forward looking; backward-looking; NKPC

\section{Introduction}

The dynamic economy of ASEAN member countries with high growth of outputs requires inflation control, which is based on a good understanding of inflation. Various studies on inflation using national data aggregation have been conducted, but only a few studies have concern about inflation and built a model of inflation based on data from a community of country (Wardhono et al. 2017). Ideally, the research that examines dynamic inflation using panel data of a community of country is also conducted to better understand inflation. The research is important because ASEAN is a community of big countries with regional growth differences that cause variations in inflation. These variations certainly cannot be seen using aggregate data but can be seen using data of each country. In addition, the calculation of consumer price index compiled by regions of the countries shows that inflation is a phenomenon of the rise in general price level.

Moreover, quoting Mehrotra et al. (2007), research using provincial data is important for big countries because the provinces throughout the country have different institutions, economic performance, and level of market development. Economic obstacles between regions, for example, trade obstacles, can also be a source of differences in inflation formation process (Wardhono et al. 2018). Furthermore, inflation differences between regions reduce the ability of a region to adjust the economic shocks. In addition, the role of inflation and inflation expectations in various areas that have various inflation dynamics also influences the effectiveness of monetary policy. 
Research on interprovincial inflation has been carried out by Mehrotra et al. (2007) using data of China. In their research, they found the variation of inflation in each province and the forward-looking inflation component in 22 of the 29 provinces studied. Likewise, Chaban and Voss (2012) who examined inflation in Canada found a variation of inflation in 10 provinces. The contribution of this research compared to previous inflation studies is the use of panel data of 5 ASEAN countries, in contrast to Mehrotra et al. (2007) and Chaban and Voss (2012), who used provincial panel data. Furthermore, this research analyzes the dynamic inflation in ASEAN to use the framework of the new Keynesian Phillips curve (NKPC) model. In addition, this research will also see the effect of the output gap in each country and the monetary level in each country. Estimation of dynamic inflation used quarter-to-quarter (qtq) inflation data and the method used was the the Generalized Method of Moment (GMM) system for panel data.

\section{Literature Review}

The development model of dynamic inflation was pioneered by Calvo (1983) who created the NKPC model. The NKPC model assumes that in an imperfect competition in the market, companies can set prices based on markup above marginal cost. Furthermore, in every random period, there is a possibility $(1-\theta)$ for companies to rearrange the prices and a possibility $\theta$ for the companies not to change the prices. This condition can be written as

$$
p_{t}=\theta p_{t-1}+(1-\theta) p_{t *},
$$

where the aggregate price level, $p_{t}$, consisting of rearranged prices, $p_{t} *$, and the old prices, $p_{t-1}$ that did not change. The company's choice to rearrange the prices can be expressed in the following equation:

$$
p_{t} *=\mu+(1-\theta \beta) \sum_{k=o}^{\infty}(\theta \beta)^{k} \theta p_{t-1} E_{t} m c_{t+k}^{n}
$$

where $\mu$ is the value of optimal markup, $\beta$ is the discount factor, and $m c_{t+k}^{n}$ is nominal marginal cost. The sigma sign in Equation (2) shows the new prices, which are arranged based on the whole expectations $m c_{t+k}^{n}$. In addition, companies can also choose not to change the prices based on the weighted value of the expectation of future nominal marginal costs. Based on the conditions, Equations (1) and (2) can be arranged in a new equation that generates a new Keynesian Phillips curve (NKPC) model as follows:

$$
\pi_{t}=\beta E_{t} \pi_{t+1}+\frac{(1-\theta)(1-\theta \beta)}{\theta}\left(m c_{t}+\mu\right),
$$

where inflation relates to expectations of future inflation and the difference in real marginal cost of its optimum level. In the general condition, aggregate real marginal cost is proportional to the difference between actual output and potential output. By this assumption, the NKPC becomes

$$
\pi_{t}=\beta E_{t} \pi_{t+1}+\lambda y_{t}
$$

where $y_{t}$ is the output gap, i.e., actual output minus potential output, $\left(y_{t}^{a}-y_{t}^{*}\right)$, and $\lambda=\frac{(1-\theta)(1-\theta \beta)}{\theta}$.

For policy implications, Rudd and Whelan $(2002,2005 a)$ state that NKPC inflation is influenced completely by forward-looking behavior. There is no inertia in inflation, which means that there is no structural impact of the past inflation on inflation. Then, solving the Equation (4) in a rational assumption obtains the equation:

$$
\pi_{t}=\lambda \sum_{k=0}^{\infty} \beta^{k} E_{t} y_{t+k}
$$


There are at least three policy implications of the NKPC model presented by Rudd and Whelan (2005a, 2005b). The first is the absence of inertia in the inflation model. Inflation is influenced entirely by forward-looking behavior. Second, the involvement of the lag inflation variable as a proxy for the future value from the output gap affecting inflation is not applicable. According to the supporters of NKPC, if the central bank is able to maintain the inflation target with credible policies, the role of lag inflation in the expectation becomes small. In this situation, inflation can be controlled at a low cost. However, if the policy is not credible, inflation expectations are compiled by the public based on the last occurrence of inflation (lag) and not the central bank's announcement. The latter policy implication is the occurrence of misleading nature of the non-accelerating inflation rate of unemployment (NAIRU)-based analysis, so NAIRU cannot be used as a macroeconomic policy guideline. Estimation of time-varying NAIRU showing low inflation can be explained by a decrease in NAIRU. Implicitly, this means that the central bank can increase the economic activities without having to increase inflation. In fact, models (4) and (5) show that there is a positive effect between output gap and inflation.

\section{Methodology}

This research used panel data of 5 countries that exist in ASEAN, ranging from year 2005 quarter 1 through year 2018 quarter 4 . Most of the data were taken from the central bank of each country in ASEAN, ASEAN secretariat, International Monetary Fund (IMF), and the World Bank. Some of the variables used in the model are listed in Table 1.

Table 1. Variable definitions.

\begin{tabular}{|c|c|c|c|}
\hline Variable & Symbol & Unit & Note \\
\hline Inflation & $\pi_{i, t}$ & Percent & Quarter-to-quarter provincial inflation \\
\hline Actual output & $y_{i t}^{a, t}$ & IDR billion & Real GDP \\
\hline Potential output & $y_{i t}^{*}$ & IDR billion & $\begin{array}{l}\text { Obtained using Hodrick-Prescott }(\mathrm{H}-\mathrm{P}) \text { filter } \\
\text { method }\end{array}$ \\
\hline Output gap & $y_{i t}$ & Percent & $y_{i t}=\frac{\left(y_{i t}^{a}-y_{i t}^{*}\right)}{y_{i t}^{*}} \times 100 \%$ \\
\hline $\begin{array}{l}\text { Changes in the amount of } \\
\text { real money supply }\end{array}$ & $\Delta M_{i t}$ & IDR billion & $\begin{array}{l}\Delta M_{i t} \text { is a real change in currency }\left(\Delta K_{i t}\right) \text { plus } \\
\text { the change in real demand deposits }\left(\Delta G_{i t}\right) . \Delta K_{i t} \\
\text { is the current currency flow in the central bank } \\
\text { and } \Delta G_{i t} \text { is the changes in deposits in each } \\
\text { country. }\end{array}$ \\
\hline$\Delta M_{i t}$ compared to $y_{i t}^{a}$ & $m_{i t}$ & Percent & $m_{i t}=\frac{\Delta M_{i t}}{y_{i t}^{a}} \times 100 \%$ \\
\hline
\end{tabular}

The following are the dynamic inflation models used in this research and refer to research conducted by Gali and Gertler (1999).

$$
\begin{gathered}
\pi_{i, t}=\gamma_{b} \pi_{i, t-1}+\gamma_{f} \pi_{i, t+1}+\lambda y_{i t} \\
\pi_{i, t}=\gamma_{b} \pi_{i, t-1}+\gamma_{f} \pi_{i, t+1}+\lambda y_{i t}+\delta_{m} m_{i t}
\end{gathered}
$$

where $\pi_{i t}$ is inflation, $y_{i t}$ is output gap, and $m_{i t}$ is monetary aggregate. Furthermore, $\gamma_{b}$ and $\gamma_{f}$ are defined as backward-looking and forward-looking parameters. The selection of estimation method is based on the NKPC model. Equation (8) can be rewritten as follows:

$$
\pi_{t}=\lambda y_{t}+\gamma_{f} E_{t}\left\{\pi_{t+1}\right\}+\gamma_{b} \pi_{t-1}+u_{t}
$$

where $y_{t}$ is the output gap $\left(y_{i t}^{a}-y_{i t}^{*}\right)$. In practice, $E_{t}\left\{\pi_{t+1}\right\}$ is usually converted into $\pi_{t+1}-\eta_{t+1}$, where $\eta_{t}$ symbolizes a step forward of forecast error of inflation (Vinod 2010). The changes lead to the equation changing into

$$
\pi_{t}=\gamma_{0}+\lambda y_{t}+\gamma_{f} E_{t}\left\{\pi_{t+1}\right\}+\gamma_{b} \pi_{t-1}+\varepsilon_{t}
$$

Thus, an endogeneity problem arises because the error correlation $\varepsilon_{t}$ with the regressor results in inconsistent estimates $\hat{\gamma}_{0}, \hat{\lambda}, \hat{\gamma}_{f}$, and $\hat{\gamma}_{b}$. If there is a problem of endogeneity, then 
Ordinary Least Square (OLS) is inconsistent and the estimation method that should be used is GMM.

Mileva (2007) describes how the data panel and a model similar to Equation (8) can face problems. First, the endogeneity problem can appear where the regressor is correlated with the error term. Second, time-invariant characteristics of the province (fixed effect), such as geography and demography, may be correlated with the explanatory variables. The fixed effect in the error term consists of the observed and unobserved effects (Sadik-Zada 2019). Third, the emergence of a lag variable increases autocorrelation. Fourth, panel data have a short time dimension and relatively large space dimension. To solve the problem that arises, Mileva (2007) suggests using the Arellano-Bond GMM estimator or GMM system.

\section{Results and Analysis}

The testing of data integration order is made toward inflation-quarter data $\pi_{i t}$, the output gap $y_{i t}$, and monetary variable $m_{i t}$. Order integration testing of panel data used the IPS test of Im, Peseran, and Shin (2003), LLC test of Levin, Lin, and Chu (2002), and Augmented Dickey-Fuller ADF Fisher test and Phillips-Perron Test (PP) Fisher test of Maddala and Wu (1999).

The overall unit root tests, either LLC, IPS, ADF Fisher, or PP Fisher, indicate that the null hypothesis, which contains a unit root, was rejected, so it is concluded that all data are integrated at the order level. The test results in Table 2 show that $p$-value is entirely under $5 \%$, so it is concluded that there were no root units in all variables of level order. Because the data are integrated at the level order, level data in the estimated GMM model are used.

Table 2. Panel data unit root test at level order.

\begin{tabular}{cccccc}
\hline Variable & LLC & IPS & ADF Fisher & PP Fisher \\
\hline & & $\mathbf{H}_{\mathbf{0}}=$ Unit Root & $\mathbf{H}_{\mathbf{0}}=$ Unit Root & $\mathbf{H}_{\mathbf{0}}=$ Unit Root & $\mathbf{H}_{\mathbf{0}}=$ Unit Root \\
\hline \multirow{2}{*}{$\pi_{i t}$} & Statistik & -24.7837 & -22.2389 & 562.340 & 527.364 \\
& (prob) & $(0.0000)^{*}$ & $(0.0000)^{*}$ & $(0.0000)^{*}$ & $(0.0000)^{*}$ \\
$y_{i t}$ & Statistik & -19.4621 & -27.8572 & 512.534 & 498.827 \\
& (prob) & $(0.0000)^{*}$ & $(0.0000)^{*}$ & $(0.0000)^{*}$ & $(0.0000)^{*}$ \\
$m_{i t}$ & Statistik & -17.5328 & -23.7583 & 482.837 & 852.723 \\
& (prob) & $(0.0000) *$ & $(0.0000)^{*}$ & $(0.0000)^{*}$ & $(0.0000)^{*}$ \\
\hline
\end{tabular}

Note: * significance at level $\alpha 5 \%$.

Gali and Gertler (1999) compare the results of estimated NKPC models to show that the use of output gap in dynamic inflation models is not appropriate. In the explanation, they use a pair of independent variables of future inflation $\pi_{t-1}$ and output gap $y_{i t}$ in the NKPC model. The estimation results of the NKPC using independent variable $\pi_{t+1}$ and the variable of part of labor income share $\left(s_{t}\right)$ show estimation of a positive parameter for $\pi_{t+1}$ and $\left(s_{t}\right)$. The econometric success provides the basis for Gali and Gertler (1999) and Gali et al. (2005) not to use the output gap, but part of the labor income in the model. Part of labor income is the labor income percentage compared to the total output of economy.

The NKPC model, developed by Gali and Gertler (1999), explains that inflation expectations and lag inflation simultaneously affect the prevailing inflation. This model assumes that the company determines the price level based on information on the past inflation (backward-looking rule-of-tumb), while the rest behaves as forward-looking.

Table 3 shows the estimated NKPC in model A using GMM with an instrument variable. Estimating the equation of the NKPC indicates backward-looking, forwardlooking parameter estimation, and the significant output gap at $\alpha=5 \%$, which is indicated by a $p$-value of all parameters less than $5 \%$. The $p$-value for the J-statistic is also greater than $5 \%$. The null hypothesis, which states that there is no overidentification, is accepted. Model A also shows the direction of the coefficient backward-looking, forward-looking, and the output gap according to the theory (positive). 
Table 3. Dynamic inflation model based on the New Keynesian Phillips Curve (NKPC).

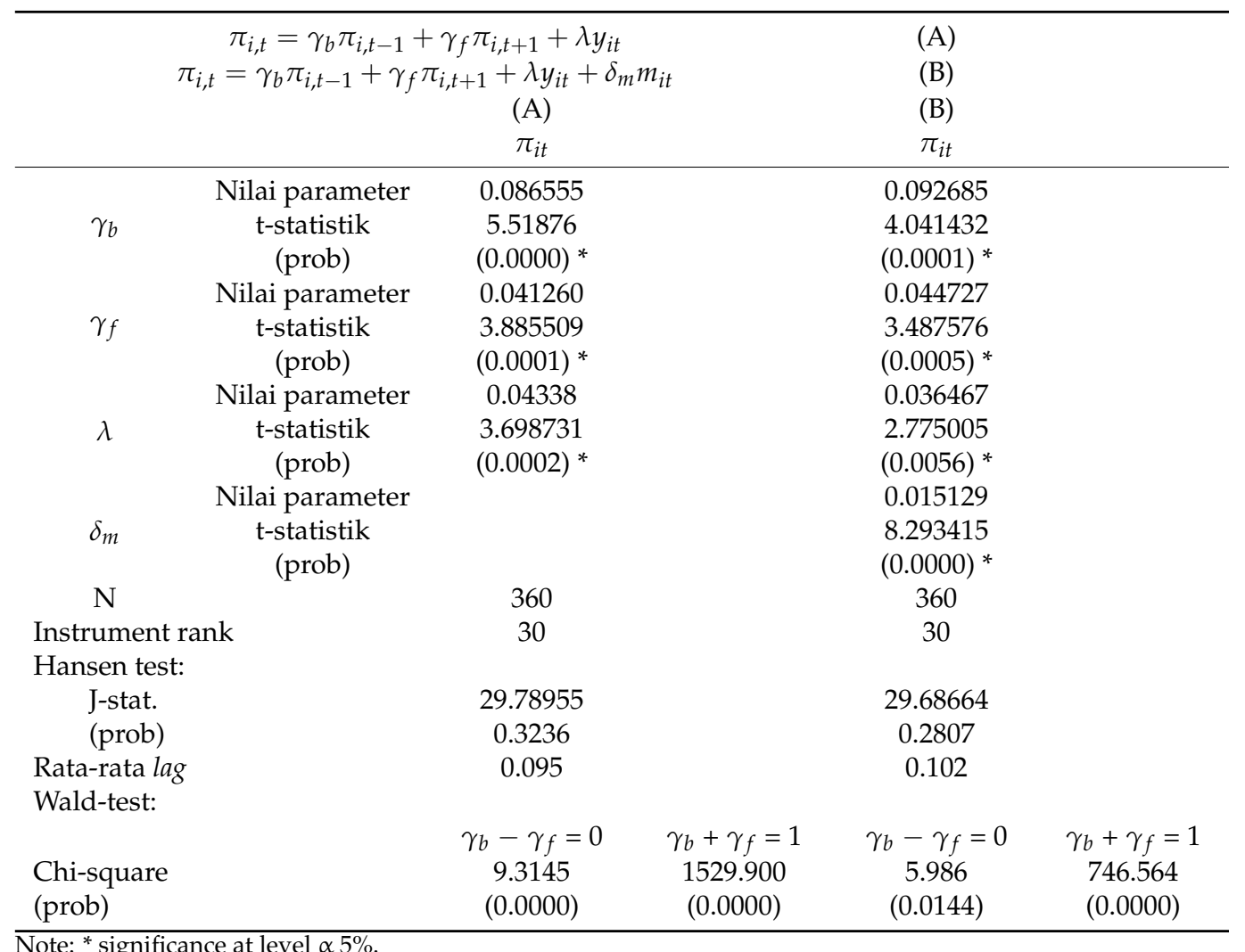

Results of the estimated NKPC model indicate the pattern of formation of inflation expectations is backward-looking and forward-looking. This means that inflation expectations are influenced by the experience of the past inflation and estimation of inflation expectations in the future. Notwithstanding the foregoing, it can be seen that the backwardlooking parameter is greater than forward-looking. Hypothesis $\gamma_{b}-\gamma_{f}=0$ or $\gamma_{b}=\gamma_{f}$ is also rejected by the Wald test. The chi-square value (9.31) and prob-value (0.0000) indicate that the value $\gamma_{b}$ is not equal to $\gamma_{f}$. Based on the value of the parameter and Wald test, it is found that the behavior of backward-looking is more dominant in the formation of inflation expectations than that of forward-looking behavior.

Testing the number of parameters of backward-looking and forward-looking, the same as one $\gamma_{b}+\gamma_{f}=1$, is also performed using the Wald test. This test is made to determine whether the establishment of expectations is perfect or full. The results of the Wald test with chi-square (1529.9) value and $p$-value (0.000) conclude that the hypothesis stating $\gamma_{b}+$ $\gamma_{f}=1$ is rejected. This means that the formation of inflation expectations is not full and in the long-term, the Phillips curve is not vertical. The test results indicate that inflation is also influenced by the output gap. The conclusion of the Wald test results is in line with the significant value of the output gap parameter $\lambda$, and this means that the output gap affects inflation.

NKPC estimation results also show the persistence of inflation in ASEAN. The average time of inflation adjustment of 0.095 , which is calculated based on the method presented by Koyck (1954) (in Gujarati (2003)) shows that the average length of time of inflation adjustment is 0.095 quarter or approximately 1.1 week. This value indicates the low level of inflation persistence.

Model B shows the estimated results of the NKPC with additional monetary variables. Estimation of model B shows the estimation of backward-looking and forward-looking parameters, the output gap, and monetary variables is significant at $\alpha=5 \%$, which is indicated by $p$-value of all parameters less than $5 \%$. The $p$-value for J-statistic is also greater than $5 \%$. The null hypothesis, which states that there is no overidentification, is accepted. Table 3 
also shows the direction of the coefficient of backward-looking and forward-looking, and the output gap of model B is in accordance with the theory (positive).

Of the estimated model B, it is found that the monetary variable turns out to affect inflation. This means that if relative money supply compared to GDP increases, the inflation will rise, while if it is decreased, it will lead to inflation decrease. In the estimation of model $\mathrm{B}$, it can be seen that the significance level of the backward-looking parameter is always significant at $\alpha=5 \%$. This level of significance is the same as in model A. This means that the additional explanatory variable causes the reduced strength of the forward-looking parameter in influencing inflation.

Even if the level of significance of the forward-looking parameter declines, the estimated results of the NKPC model with a fixed monetary variable shows backward-looking and forward-looking determines the pattern formation of inflation expectations. Inflation is influenced by the experience of inflation in the past time and also the estimated inflation expectations in the future by the backward-looking parameter value greater than that of the forward-looking parameter.

Wald test results with $p$-value (0.000) for model B concludes that the hypothesis which states that $\gamma_{b}+\gamma_{f}=1$ is rejected. This means that the formation of inflation expectations is not full in the NKPC model with additional monetary variables. Besides, the meaning of rejection of the hypothesis in the long term of the NKPC model is not vertical. The test results indicate that inflation is also affected by other significant variables in the model. In addition, the average time of inflation adjustment for model $\mathrm{B}$ is 0.102 . Similar within the NKPC model (model A), the average time needed to adjust the inflation is about one week. This value indicates the low level of inflation persistence.

\section{Discussion}

According to the baseline NKPC, inflation is mainly an expectations phenomenon-if the central bank controls future inflation expectations, it controls the present value of inflation (Carré 2008). This explains why the expectations channel of transmission is central to monetary policy: "markets do the job" instead of the central bank. It is also why "expectations management" is so crucial in the modern view of optimal monetary policy under the inflation targeting regime-the expectations management is the root of monetary policy efficiency.

Consistency of positive direction parameter estimation of the Phillips curve and NKPC shows that the opinions of Gali and Gertler (1999) and Gali et al. (2005), which state that the output gap cannot be a proxy for economic activities, cannot be accepted. Based on these results, the use of the output gap in the estimated dynamic inflation model in this research may be confirmed. Moreover, in all estimated models, significant values of the output gap are obtained.

The conclusion that the output gap in ASEAN countries can be accepted as factors affecting inflation is the same as the conclusion of research conducted by Mehrotra et al. (2007). Variable significance of national output gap on inflation indicates that demand and supply of outputs in ASEAN are important variables that explain dynamic inflation. The high national economy in ASEAN, which causes actual output to be above its potential, has an implication on inflation in each country, and vice versa.

Based on the estimated NKPC model, either in reduced form (model A) or after the addition of monetary shock variable (model B), it is found that estimation parameters of forward-looking $\gamma_{f}$, or backward-looking $\gamma_{b}$, are entirely significant and marked positive. These results prove that the formation pattern of inflation expectations is backward-looking and forward-looking. This means that the inflation expectations are influenced by the experience of the past inflation and inflation expectations in the future.

Even if inflation is influenced by the behaviors of backward-looking and forward-looking, the NKPC estimation model results show that the behavior of backward-looking is more dominant than that of forward-looking. However, in all estimated models, the dominant value of component of backward-looking decrease when the explanatory variables in the 
NKPC model is coupled with monetary variables. The findings of the dominance of backward-looking behavior is different from the predictions of the NKPC model and previous studies conducted by Gali and Gertler (1999); Gali et al. (2005); Abbas and Sgro (2011); and Mehrotra et al. (2007).

The results of the estimation of the model NKPC also find that the dynamics of inflation is not only influenced by expectations that underlie the behavior of the backwardlooking and forward-looking. Other explanatory variables such as the output gap and monetary and cyclical variables also influence inflation.

The conclusion states that the money supply in ASEAN that has an effect on regional inflation is the same as the conclusion of previous research that examined the effect of the amount of money on inflation. These results indicate that the regulation of the money supply in ASEAN can be used to control inflation and to prescribe monetary policy at the national level. The final conclusion that can be drawn from the estimation results is that the level of inflation persistence is low. The average value for inflation adjustment time is about one week. This means that if there is a shock that causes inflation to differ from its equilibrium point, economic actors will quickly adjust the existing inflation back to its equilibrium value.

Since 2002, the Philippines has been adopting inflation targeting framework as its guide in reaching price stability for the purpose of determining monetary decisions. The Philippines adopted a floating exchange rate system in 1970 (Wardhono et al. 2014). This was caused by the existence of government consideration toward a steady exchange rate system that became a treasure of an overexchange rate fluctuation. The implication of the floating exchange rate system was also consistent to ITF. Through this path, exchange rate movement was impacted by actual inflation and expected inflation (Report, Bangko Sentral NG Pilipinas 2015).

Indonesia has been adopting an inflation targeting framework since 2005, which previously used monetary policy that applied base money as a policy framework. Indonesia has begun to implement a floating exchange rate system since 1997 until now. The purpose of the policy of Bank Indonesia is to maintain exchange rate stability and safeguard the Rupiah value stability, in order to maintain stability in the prices of goods and services reflected in inflation (Wardhono et al. 2016). A floating exchange rate policy is also consistent with the implementation of the monetary policy framework, i.e., inflation targeting framework. Malaysia is one of the ASEAN members that does not implement an inflation targeting framework as a monetary decision. Malaysia uses the interest rate framework as one of its national monetary decision targets. The main instrument of its monetary decision is the overnight policy rate (OPR). Malaysia seems to implement a flexible inflation target decision, although it does not officially adopt IT as its decision guide. In 2002, Malaysia used the steady exchange rate system; later, on 21 July 2005, it was changed to a floating exchange rate system. This transformation is a response of a structural change that happened in the domestic or international region. Since 2000, Thailand has adopted an inflation targeting framework. Thailand adopted a floating exchange rate system in July 1997, and the system is also consistent with the inflation target policy framework (ITF) adopted by Thailand in 2000. The implication of inflation targeting framework and the floating exchange rate system indicate that the Baht exchange rate is determined by the market. In implementing the system, the Bank of Thailand does not target a fixed amount for the exchange rate, but the Bank of Thailand will intervene in case of excessive volatility, as the Bank of Thailand is consistent with the policy of an inflation targeting framework.

\section{Conclusions}

The result of the estimated NKPC model in ASEAN found that the dynamics of inflation is not only influenced by expectations that underlie the behaviors of backwardlooking and forward-looking. Other explanatory variables such as the output gap and monetary variables also influence inflation. The conclusion stating that the amount of money supply in each country influences inflation is the same as the conclusion of previous 
research that examines the influence of money on inflation. These results suggest that the regulation of money supply in each country can be used to control inflation, such as monetary policy prescriptions at a national level.

The final conclusion that can be drawn from the results of estimation is that the level of inflation persistence is, in fact, low. The average value of the inflation adjustment time is about one week. This means that if there is a shock that causes inflation to be different from the point of equilibrium, the economic actors quickly adjust the existing inflation back to the equilibrium value.

Thus, the policy that can be taken in supporting the economy in ASEAN is the policy of inflation control that can be made by optimizing the control policy of monetary aggregates (money supply) in each country. The central bank can set the target of money supply to control inflation. Both fiscal and monetary policies must be credible and trusted by economic agents because they determine the price fluctuations.

Author Contributions: Conceptualization, A.W.; methodology, A.W. and M.A.N.; software, Y.I. and M.A.N.; validation, A.W.; formal analysis, C.G.Q. and M.A.N.; investigation, Y.I.; resources, Y.I. and C.G.Q.; data curation, M.A.N.; writing-original draft preparation, A.W. and M.A.N.; writingreview and editing, M.A.N. and C.G.Q.; visualization, Y.I. and M.A.N.; supervision, A.W.; project administration, M.A.N.; funding acquisition, A.W. All authors have read and agreed to the published version of the manuscript.

Funding: This research received no external funding.

Institutional Review Board Statement: Not applicable.

Informed Consent Statement: Not applicable.

Data Availability Statement: Not applicable.

Acknowledgments: We would like to thank Bank Indonesia as the Indonesian Central Bank and Central Bureau of Statistics of Indonesia, which has provided data support to us during our research.

Conflicts of Interest: The authors declare no conflict of interest.

\section{References}

Abbas, Syed Kanwar, and Pasquale M. Sgro. 2011. New Keynesian Phillips Curve and Inflation Dynamics in Australia. Economic Modeling 28: 2022-33. [CrossRef]

Bangko Sentral NG Pilipinas. 2015. Report on Philippine External Debt. In Inflation Targeting. Manila: Bangko Sentral NG Pilipinas.

Calvo, Guillermo A. 1983. Staggered Prices in a Utility Maximizing Framework. Journal of Monetary Economics 12: 383-98. [CrossRef]

Carré, Emmanuel. 2008. The New Keynesian Phillips Curve: A Meta-Analysis. Orléans: Universite d'Orlans.

Chaban, Maxym, and Graham M. Voss. 2012. National and Provincial Inflation in Canada: Experiences under Inflation Targeting. Working Paper. Victoria: Department of Economics University of Victoria.

Gali, Jordi, and Mark Gertler. 1999. Inflation Dynamics: A Structural Econometric Analysis. Journal of Monetary Economics 44: 195-222. [CrossRef]

Gali, Jordi, Mark Gertler, and J. David Lopez-Salido. 2005. Robustness of Estimates of the Hybrid New Keynesian Phillips Curve. Journal of Monetary Economics 52: 1107-18. [CrossRef]

Gujarati, Damodar N. 2003. Basic Econometrics, 4th ed. New York: McGrow-Hill.

Mehrotra, Aaron, Tuomas Peltonen, and Alvaro Santos Rivera. 2007. Modelling Inflation in China: A Regional Perspective. Working Paper Series, No. 829/November 2007; Frankfurt: European Central Bank.

Mileva, Elitza. 2007. Using Arellano-Bond Dynamic Panel GMM Estimator in Stata: Tutorial with Example Using Stata 9.0 (xtabond and $x$ tabond2). The Bronx: Lecture Materials, Economics Department, Fordham University.

Rudd, Jeremy, and Karl Whelan. 2002. Should Monetary Policy Target Labor's Share of Income? In Federal Reserve Bank of San Francisco Proceedings. San Francisco: Federal Reserve Bank of San Francisco.

Rudd, Jeremy, and Karl Whelan. 2005a. Modelling Inflation Dynamics: A Critical Review of Recent Research. Staff Working Paper, The Finance and Economics Discusson Series (FEDS). Washington, DC: Federal Reserve Board.

Rudd, Jeremy, and Karl Whelan. 2005b. New Tests of the New-Keynesian Phillips Curve. Journal of Monetary Economics 52: $1167-81$. [CrossRef]

Sadik-Zada, Elkhan Richard. 2019. Distributional Bargaining and the Speed of Structural Change in the Petroleum Exporting Labor Surplus Economies. The European Journal of Development Research. 32: 51-98. [CrossRef]

Vinod, Hrishikesh D. 2010. GMM and OLS Estimation and Inference for New Keynesian Phillips Curve. Discussion Paper No. 2010-02. The Bronx: Departemen of Economics-Fordham University. 
Wardhono, Adhitya, Agus Salim, and Ciplis Gema Qori'ah. 2014. The Effects of European Bilateral Debt Crisis on International Banking Finance Behavior in the Philippines and Indonesia. International Journal of Economic Perspectives 8: 41-51.

Wardhono, Adhitya, Ciplis G. Qori'Ah, and Yulia Indrawati. 2016. The determinants of financial inclusion: Evidence from Indonesian districts. International Journal of Economic Perspective 10: 472-83.

Wardhono, Adhitya, Badara Shofi Dana, and M. Abd Nasir. 2017. Rethinking the Exchange Rate Disconnect Puzzle Theory in ASEAN-6. Economic Journal of Emerging Markets 9: 98-103. [CrossRef]

Wardhono, Adhitya, Dwi Arisandi, and M. Abd Nasir. 2018. Empirical Study of Scapegoat Theory Paradigm in the Exchange Rate Variable in the ASEAN 5. International Economic Journal 32: 102-19. [CrossRef] 